\title{
The Contrary Effect of Collaborative Writing on ESL Students' Vocabulary Acquisition
}

\author{
Elnaz Valaei Bakhshayesh ${ }^{a}$
}

\begin{abstract}
Writing task is an integral part of education in ESL (English as a Second Language) at the foundation level. It has been observed that foundation level 3 students of Arab Open University have an insufficient knowledge of vocabulary which is reflected on their writing, as their usage of vocabulary is confined to a number of limited common words. This research explores the effect of collaborative writing on students' vocabulary acquisition. All the writing tasks were related to educational topics in order to provide students with the lexical items related to the same subject. This study took place in one of the foundation level 3 classes at Arab Open University, Oman branch. Fourteen anonymous Arab students for whom English is considered as the second language participated in this study. All students are in the intermediate level of English language proficiency. For each writing task, five collocations were selected to be taught in the class over a period of five weeks. The achieved outcomes revealed contrary results to the previous studies that had shown the effective impact of collaborative writing. This study has discussed the contrary impact of collaborative writing on improving the learners' vocabulary acquisition in addition to the challenges students faced during collaborative writing task. Finally, this research provides recommendations for the effective collaborative writing in the foundation students' language proficiency.
\end{abstract}

\section{Keywords}

Collaborative writing, L2 vocabulary acquisition, challenges

In second language acquisition, both proper structure and vocabulary are the basis for building up students' knowledge of the second language. According to Nation and Laufer (1995: 307), vocabularies in L2 have effective roles in producing a "well-written composition". Shen (2008: 139) pointed out that lack of vocabulary knowledge acts as a hurdle in reading. With this theory, he carried out a research on two aspects of vocabulary knowledge in EFL (English as a Foreign Language) reading performance. According to his study, vocabulary knowledge should consist of two aspects: "vocabulary breath" and "depth of vocabulary". "Vocabulary breath" refers to the number of words the learner knows and "depth of vocabulary" refers to the thorough and systematic knowledge of the word such as spelling, pronunciation, meaning, and frequency.

Based on the father of the social constructivist's theory of learning, Vygotsky (1978), learning occurs in a social context where there is interaction between the top achievers and low achievers. The latter group can benefit from the former group by working together and building up the knowledge which is the result of their collaboration. This study, based on Vygtosky's social constructivism approach, attempts

${ }^{a} A r a b$ Open University, Muscat, Oman

\section{Correspondent Author:}

Elnaz Valaei Bakhshayesh, P.O. Box 1596, P.C.: 130, Azaiba Sultanate of Oman 
to investigate how learning occurs in social context, such as class, for Arab language learners in foundation level of English. Since the Arab Open University students possess insufficient vocabulary knowledge in English which particularly impedes their ability in writing proper compositions, this research has been carried out with the aim of introducing new words all revolving around the same topic, i.e. education. Both individual and collaborative approaches were adopted to explore the effects of collaborative writing on students' improvement in their acquisition of the new vocabularies. This study answers the following questions:

(1) Do Arab language learners benefit from the collaborative or individual writing?

(2) What challenges do Arab language learners face with the collaborative writing task?

\section{LITERATURE REVIEW}

Social constructivism has effectively revolutionized the traditional mode of learning and teaching by transforming students' positions from "passive receivers of ideas" to "autonomous learners" (Yang and Wilson 2006: 364). Watson (2001: 143) believed that "intellectual progress" occurs mainly through interactions and dialogues. Accordingly, social interactions promote students' "social skills, social understanding, metacognitive awareness" and also teach them how to explain and develop their ideas. Supporting social constructivist perspective, Storch (2005: 154) asserted that students' social interactions in learning environment fundamentally not only promote "co-construction of knowledge", but also foster the sense of "co-ownership" in students. This means that students, through the process of writing activity, share the responsibility over the produced text together.

The main point in collaborative learning is to guide students to learn and build the knowledge of the language together through interactions. In social interactions, "interaction and dialogue" both have fundamental roles in "knowledge generation" (Churcher, Downs, and Tewksburry 2014: 35). In the same vein, Murphy and Jacobs (2000: 232) pointed out that through "positive interdependence", students feel responsible for the achievement or failing of their group. "Group members realize that each member's efforts benefit not only themselves but all other group members as well. Positive interdependence provides a feeling of support within the group". For Huffman (2010: 31-32), "Collaborative learning is championed for its contributions to the learners' social and individual development, as students engage collectively in building interpersonal skills, problem-solving, constructing shared understandings, and also strengthen their relationship to the community at large". K. A. Jones and J. L. Jones (2008: 64) had a futuristic perspective toward collaborative learning. As their study highlights students' future workplace, by working with others, students not only learn to constructively assess others' work but more importantly, they generate a sense of "accurate self-assessment" of their own work as well.

The role of the language is largely highlighted when it is used as an effective tool to create interactions in social contexts. As cited in Al Ajmi and Ali (2014), Swain (2006: 3) extended the definition of "languaging" as "the process of making meaning and shaping knowledge and experience". It is elaborately discussed that through collaborative writing, students' interactions with each other provide them with a chance to discuss the language they are using. Speck (2002: 34), by pointing out the nature of collaborative writing, he highlighted the significance of adopting collaborative writing in the classroom as this was an active mode of learning. The researcher has broadened the perspective of collaborative writing from classroom settings to students' future lives. Accordingly, cooperative writing is an activity practiced inside the class to promote students' analytical thinking and also prepare them "to function effectively as writers" in their prospective workplaces. 


\section{EMPIRICAL STUDIES}

The studies that have investigated Collaborative Writing (CW) are reviewed below which are organized by theme.

The impact of collaborative writing on students' grammatical accuracy examined in a study conducted by H. Meihami, B. Meihami, and Varmaghani (2013) indicated an impressive improvement in the grammatical accuracy of the students who worked in groups. Amirkhiz et al. (2013: 477) conducted a study focusing on the "verbal interaction" among four female Malaysian and four female Iranian students, with equal language proficiency in English. Students' dialogues during the collaborative writing were audio-recorded. The results indicated that Iranian students focused more on the "meta-linguistic features of language", while Malaysian participants paid more attention to the "communicative aspect of language". When the reasons of these variables were discussed, it was found out that students' previous learning experiences in different contexts had an immense impact on their peer interaction.

Mulligan and Garofalo (2011) conducted a research on collaborative writing at a private university in Kyoto to study students' feedbacks of collaborative writing methodology through an assessment survey. According to the questionnaire, designed by the teacher at the end of the semester, it was found out that most of the students had positively benefited from the collaboration in their writing process. The authors categorized students' positive feedbacks of peer edition into five categories: (1) Students could improve their social skills; (2) They did not experience stress or strain; (3) They gained more motivation in their pair interactions; (4) The content of their writings was improved; and (5) There was more grammatical and structural accuracy in their writings. In this research, more attention is given to analyze students' feedback of peer collaboration and correction which can guide the teachers to modify their programs.

The study conducted by Dobao (2014), examined the vocabulary learning by comparing L2 learners' performance in pair and small group work. The focal aim of the study was to investigate the influence of the number of participants in a collaborative writing task on vocabulary learning. The participants of this study were 110 learners of Spanish as a foreign language of the same intermediate level. Each group and pair of students was required to create their own stories by rearranging the pictures the teacher had given them. Each group and pair was asked to produce their texts collaboratively. The study mainly focused on lexical LREs (Language-Related Episodes) and also grammatical problems. The results of the pair and group interaction showed that students, through talking, in group work could produce more lexical LREs than participants in the pair work since learners could share more lexical knowledge together.

However, students do not always exhibit positive attitudes about cooperation and collaboration in learning. Despite the abundant literature in favour of collaborative writing, some scholars have a contrasting view. According to the research carried out by Shafie et al. (2010), Malaysia University novice writers faced challenges in negotiating ideas and working collaboratively which built a stressful learning environment for the students. Poor language knowledge was also additional factor in producing contrary results in collaborative writing task among Malaysian students. Chisholm (1990) could identify four key issues students face in collaborative writing projects. According to his research, some students resist to participate in group work for various reasons such as laziness, shyness, or very simply, they are reluctant to be fully committed to the collaborative task. Some students might feel uncomfortable and anxious with group work as it may intrude their privacy which leads to students' discouragement from group work.

The objective of this study is to discuss the contrary effect of $\mathrm{CW}$ in addition to the problems 
Arab language learners faced in collaborative writing task which affected their output performance in vocabulary acquisition.

\section{RESEARCH METHODOLOGY}

The present study aimed to investigate vocabulary learning in both individual and pair writing task. This research was conducted over a period of five weeks during the regular teaching time. The first week, students were required to produce a text on "advantages of studying abroad". The achieved results revealed students' poor vocabulary knowledge which had impeded expressing ideas properly. From the second week, one writing task per week was introduced in the classroom; all the writing tasks were related to educational topics. Each task included five new words inserted within collocations. The number of individual participants was 14 after which seven pairs were created.

The tasks started by giving the students the chance to write individually on one day followed by group writing tasks on the following day. The new words were introduced contextually so that the students would familiarize themselves on how to use and apply such terms appropriately. In writing task, one and two students were asked to change their seats and work with different classmates. The reason was to allow students to socialize with other classmates than only working with one classmate. After the first two tasks, students were given a questionnaire to write their feedback on the collaborative writing. In the third and fourth writing task, a new strategy was implemented according to the results of the questionnaire. The results of the writing tasks were analyzed in terms of quality and frequency of usage in individual as well as collaborative writing. Students' feedback on CW has been analyzed in the "Results and Analysis" section.

\section{RESULTS AND ANALYSIS}

The concept of collaborative writing happens to be a new one for Arab Language learners as they have never been exposed to such concept previously. An additional challenge was the collocation of vocabulary that they already knew; however, only when using the vocabulary as a standing-alone word. Four topics, all related to the education, were introduced in the classroom: "The Advantages of Studying Abroad", "The Importance of Teacher's Role in the Classroom", "The Advantages of Reading Different Books", and "The Advantages of Watching Television for Children". In each writing task, five new words inserted within collocations were taught before individual and collaborative writing task.

Table 1. Writing Topic (1): Advantages of Studying Abroad

\begin{tabular}{lll}
\hline Expressions & Individual percentage & Collaborative percentage \\
\hline Live independently & $50 \%$ & $43 \%$ \\
Share interests & $64 \%$ & $71 \%$ \\
Discover new methods & $50 \%$ & $29 \%$ \\
Take decisions & $43 \%$ & $29 \%$ \\
Increase harmony and love & $71 \%$ & $57 \%$ \\
\hline
\end{tabular}

Table 2. Writing Topic (2): The Importance of Teacher's Role in the Classroom

\begin{tabular}{lll}
\hline Expressions & Individual percentage & Collaborative percentage \\
\hline Gain knowledge & $57 \%$ & $43 \%$ \\
Develop skills & $86 \%$ & $57 \%$ \\
Prepare for the future & $79 \%$ & $43 \%$ \\
Respect others & $86 \%$ & $57 \%$ \\
Improve behavior & $71 \%$ & $57 \%$ \\
\hline
\end{tabular}


As Table 1 and Table 2 present, according to the achieved results of the first and second writing task, individual percentage of the collocations is higher when compared with the collaborative one. These results, in most cases, reflect a higher level of confidence among students when they work individually.

A questionnaire was submitted to the students after the second writing task was completed; in order to collect their feedback on how they viewed the concept of collaborative writing. The questionnaire reflected the following percentages:

Table 3. Results of the Questionnaire

\begin{tabular}{lll}
\hline 1. & I speak Arabic when I am working with my classmate. & $93 \%$ \\
\hline 2. & I prefer to work alone. & $79 \%$ \\
3. & My classmate doesn't help me while writing. & $71 \%$ \\
4. & I don't learn when I write with my classmate. & $71 \%$ \\
\hline
\end{tabular}

From the above Table 3, it is clear that Question No. 1 shows the dominant role of the mother tongue that the students used while negotiating the meaning, exchanging ideas or the usage of the vocabulary which completely weakened their retention of the vocabulary they should have used in collaborative writing. Consequently, students' poor command of the second language forced them to compensate such lack by resorting to $\mathrm{L} 1$.

This questionnaire reflects the fact that nearly all students are in favour of independent writing. Question No. 2 highlights the students' tendency toward individual working, most likely due to the cultural reasons and the propensity that drives them to work with their close friends. Each student has an independent idea that they would like to express without others interfering.

Questions No. 3 and No. 4 confirm up to some extent the result of Question No. 2, moreover, it shows that students become reserved to a certain extent and they prefer not to share their knowledge with others. Students' feedback expresses clearly that they do not benefit from collaborative writing because one student who has better writing skills dominates the exercise simply because she/he knows better which minimises the other peer's self-esteem.
The students were also asked to express their views toward collaborative writing in both English and Arabic languages. According to the vast majority, working in pair especially among people who are not familiar with each other, does not produce good results; the reason is that most of them express that they prefer to work with their friends who share the same ideas and values and also belong to the same school of thought. According to other students, $\mathrm{CW}$ is not productive because they think that each individual has their own personal point of view, therefore finding a common text might result as a very difficult task to accomplish. Moreover, some of the students think that the person who writes will have the dominant role with superior linguistic knowledge.

According to Mulligan and Garofalo (2011: 9), collaborative writing is a "non-threatening" approach if it is accompanied with a mutual trust among the students along with teachers' clear guidelines. In other words, teachers need to help students to experience learning in a stress-free situation, where they can not only improve their social skills, but also develop structural accuracy in second language learning.

After the results of the second writing and the questionnaire, some changes were applied in terms of 
monitoring the students while working in groups and encouraging them to use English exclusively as the language of interaction among themselves. Teacher's presence among the students in $\mathrm{CW}$ task became more tangible by giving hints to the students to remember the newly taught words.
Prior to the $\mathrm{CW}$, students were encouraged to speak and exchange ideas about the given topic and taught words without being engaged in the writing task. Furthermore, students were given the opportunity to select their own preferred partner to work with.

Table 4. Writing Topic (3): Advantages of Reading Different Books

\begin{tabular}{lll}
\hline Expressions & Individual percentage & Collaborative percentage \\
\hline Improve creativity & $64 \%$ & $57 \%$ \\
Build self-esteem & $43 \%$ & $57 \%$ \\
Open mind & $93 \%$ & $100 \%$ \\
Discuss subjects & $29 \%$ & $29 \%$ \\
Become smart & $36 \%$ & $43 \%$ \\
\hline
\end{tabular}

Table 5. Writing Topic (4): Advantages of Watching Television for Children

\begin{tabular}{lll}
\hline Expressions & Individual percentage & Collaborative percentage \\
\hline Watch educational programs & $64 \%$ & $71 \%$ \\
Spend time with family & $71 \%$ & $86 \%$ \\
Learn about cultures & $64 \%$ & $57 \%$ \\
Being a bonding experience & $35 \%$ & $43 \%$ \\
Choose appropriate program & $43 \%$ & $43 \%$ \\
\hline
\end{tabular}

Subsequent to the applied changes, as Table 4 and Table 5 present, it appears that the latter has affected the collaborative writing positively since in most cases the percentage of the usage of the collocated vocabulary has been almost equal to the individual percentage. However, in some cases, the percentage of the individual writing is still higher which indicates students' tendency to the independent writing.

According to Shafie et al. (2010: 61), "Successful collaborative writing requires peer interaction". In this research, undeveloped social skills are considered the key factors in weakening the efficiency of vocabulary acquisition in collaborative writing tasks. Students' tendency to work independently presented particularly the lack of interpersonal skills as well as positive classroom behaviour. It is significant to develop the sense of respect and share ideas with peers before any language skills are taught. Enhancing positive classroom behaviour, resolving conflicts in collaborative tasks, and encouraging teamwork among the students are the prominent issues that stimulate students' language acquisition effectively. The results of collaborative task would tend to be more effective when students feel comfortable and motivated to work along with others due to the existence of social comfort zone that enhances creativity and consequently output.

Moreover, encouraging students to share ideas in second language can enhance the proficiency of vocabulary acquisition in CW tasks. Rollinson (2005: $25)$ wrote that through "collaborative dialogue" and communication, students are effectively able to "negotiate the meaning" with their peers which enhances students' abilities in expressing, explaining, and sharing their ideas with each other.

In order to achieve better results in collaborative writing, tutors should observe closely the group work and apply proper guidance to the students on how to use the new vocabulary in addition to encouraging 
them to use the target language as the sole means of communication. Such guidance should automatically provide learners with a higher level of confidence when using the new collocations and as a result applying them correctly. It is obvious that when students are confronted with new vocabulary or collocations for the first time, their reaction tends to be defensive and the application of such new terms is limited to sporadic output. Studying in an environment where students' anxiety and strain is diminutive, students' confidence positively grows in learning (Murphy and Jacobs 2000).

The guidance of the tutor obviously should depend on the level of the students' motivation to work in groups which results in constructive vocabulary knowledge outcome. Laufer and Hulstijn (2001: 2), stated that "elaboration" and "motivation" both equally have significant roles in learning new vocabularies in second language acquisition.

\section{CONCLUSIONS}

According to the social constructivism, language is one of the most important tools to negotiate the meaning. In this research, the first and second collaborative writing produced less encouraging results at lower levels due to the fact that students were unable to discuss the contents of the writing in proper English if any at all. Initially, the prime objective of this research was to enhance student-student scaffolding. However, after the second writing task, this approach changed into teacher-students scaffolding subsequent to the achieved results that have evidence that teacher's support was highly needed. The student-student scaffolding failed to submit significant outcome as per the revealed results showing the dominance of the students' first language in their dialogues. Students' insufficient language knowledge consequently resulted in the strong interference of the mother-tongue which mitigated the efficiency of collaborative work in vocabulary acquisition. Close observation of Arab students' $\mathrm{CW}$ and their ideas about working with another peer reveals that they prefer individual learning when they do not share the same ideas with the other peer. According to the achieved results, collaborative writing has to be questioned since it is not always applicable in all contexts of language acquisition.

\section{References}

Al Ajmi, A. A. S. and H. I. H. Ali. 2014. "Collaborative Writing in Group Assignments in an EFL/ESL Classroom." English Linguistics Research 3(2):1-17.

Amirkhiz, S. Y. Y., K. A. Bakar, A. A. Samad, R. Baki, and L. Mahmoudi. 2013. 'EFL/ESL Learners' Language Related Episodes (LREs) During Performing Collaborative Writing Tasks." Journal of Language Teaching and Research 4(3):473-479.

Chisholm, R. M. 1990. "Coping With the Problems of Collaborative Writing." Writing Across the Curriculum 2:90-108.

Churcher, K. M. A., E. Downs, and D. Tewksburry. 2014. “"Friending' Vygotsky: A Social Constructivist Pedagogy of Knowledge Building Through Classroom Social Media Use." The Journal of Effective Teaching 14(1):33-50.

Dobao, A. F. 2014. "Vocabulary Learning in Collaborative Tasks: A Comparison of Pair and Small Group Work." Language Teaching Research 18(4):497-520.

Jones, K. A. and J. L. Jones. 2008. "Making Cooperative Learning Work in the College Classroom: An Application of the 'Five Pillars' of Cooperative Learning to Post-secondary Instruction." The Journal of Effective Teaching 8(2):61-76.

Huffman, S. R. 2010. "The Influence of Collaboration on Attitudes Towards English Vocabulary Learning.” Master dissertation, University of Iowa, Ames, Iowa. Retrieved (http://lib.dr.iastate.edu/cgi/viewcontent.cgi?article $=2546 \&$ context=etd).

Laufer, B. and J. Hulstijn. 2001. "Incidental Vocabulary Acquisition in a Second Language: The Construct of Task-Induced Involvement." Applied Linguistics 22(1):1-26.

Laufer, B. and P. Nation. 1995. "Vocabulary Size and Use: Lexical Richness in L2 Written Production." Applied Linguistics 16(3):307-322.

Meihami, H., B. Meihami, and Z. Varmaghani. 2013. "The Effect of Collaborative Writing on EFL Students' Grammatical Accuracy." International Letters of Social and 
Humanistic Sciences 11:47-56.

Mulligan, C. and R. Garofalo. 2011. "A Collaborative Writing Approach: Methodology and Student Assessment." The Language Teacher, Feature Article 35(3):5-10.

Murphey, T. and G. M. Jacobs. 2000. "Encouraging Critical Collaborative Autonomy.” JALT Journal 22(2):228-244.

Rollinson, P. 2005. "Using Peer Feedback in the ESL Writing Class." ELT Journal 59(1):23-30.

Shafie, L. A., A. Maesin, N. Osman, S. Nayan, and M. Mansor. 2010. "Understanding Collaborative Academic Writing Among Beginner University Writers in Malaysia." Studies in Literature and Language 1(2):58-69.

Shen, Z. 2008. "The Roles of Depth and Breadth of Vocabulary Knowledge in EFL Reading Performance." Asian Social Science 4(12):135-137.

Speck, B. W. 2002. Facilitating Students' Collaborative Writing. Washington, D.C.: Eric Clearinghouse on Higher Education.
Storch, N. 2005. "Collaborative Writing: Product, Process, and Students' Reflections." Journal of Second Language Writing 14(3):153-173.

Vygotsky, L. S. 1978. Mind in Society. Cambridge: Harvard University Press.

Watson, J. 2001. "Social Constructivism in the Classroom." NASEN Support for Learning 16(3):140-147.

Yang, L. and K. Wilson. 2006. "Second Language Classroom Reading: A Social Constructivist Approach." The Reading Matrix 6(3):364-372.

\section{Bio}

EInaz Valaei Bakhshayesh, Master in English Literature and Language, Arab Open University, Muscat, Oman; research fields: writing error analysis, writing development, collaboration and writing. 